\title{
Adherence to antihypertensive fixed-dose combination among Egyptian patients presenting with essential hypertension
}

Mahmoud Hassanein

\begin{abstract}
Background: Many patients with hypertension require more than one drug to achieve blood pressure control. They are prescribed with fixed-dose combination (FDC) antihypertensive therapy rather than monotherapies. Although it is commonly admitted that the use of FDC may improve compliance to treatment, adherence rates in patients receiving FDCs have not been documented. Therefore, the aim of this study was to assess the adherence to treatment in patients receiving FDCs of antihypertensive medications in a real-world setting in Egypt.
\end{abstract}

Results: We conducted a multi-center cross-sectional study over a period of 1 year from Jan 2017 to Jan 2018. We included patients above 21 years old with essential hypertension who were already prescribed with an FDC of antihypertensive treatment for at least 3-month duration. We assessed the adherence to treatment by patient selfassessment using the Morisky 8-Item Medication Adherence Scale (MMAS 8).

This study enrolled 2000 hypertensive Egyptian patients. The mean age of enrolled patients was $55.8 \pm 10.9$ years. Male to female ratio was 1.08. The mean MMAS score was $6.5 \pm 1.9$. Our analysis showed that 825 (41.3\%) patients reached high adherence score, 523 (26.2\%) medium adherence, and 652 (32.6\%) low adherence.

Furthermore, Male patients showed higher adherence rate than females $(56.4 \%$ versus $43.6 \%, p<0.001)$. Out of 746 patients with controlled blood pressure (< 140/90), 387 (51.9\%) patients were highly adherent to treatment. Higher level of education was significantly associated with high adherence rate; 559 (67.8\%) patients were university graduates, 232 (28.1\%) had primary/secondary school education, and 34 (4.1\%) were illiterate $(p<0.001)$. Moreover, once daily (99.2\%) fixed-dose combination was associated with higher adherence rate than twice regimen daily (0.8\%), $p=0.03$. Multivariate logistic regression analysis showed that patients with high level of education, employed patients, and patients with controlled blood pressure have high adherence rate to medication.

Conclusions: Higher adherence to medication is associated with high level of education and employment, and it can lead to better blood pressure control. Thus, patient education programs may increase patients' adherence to their medication.

Keywords: Medication adherence, Hypertension, MMAS-8

Correspondence: mahmoud.hassanein@alexmed.edu.eg

Cardiology Department, Alexandria University, Alexandria, Egypt

\section{Springer Open}

(c) The Author(s). 2020 Open Access This article is licensed under a Creative Commons Attribution 4.0 International License, which permits use, sharing, adaptation, distribution and reproduction in any medium or format, as long as you give appropriate credit to the original author(s) and the source, provide a link to the Creative Commons licence, and indicate if changes were made. The images or other third party material in this article are included in the article's Creative Commons licence, unless indicated otherwise in a credit line to the material. If material is not included in the article's Creative Commons licence and your intended use is not permitted by statutory regulation or exceeds the permitted use, you will need to obtain permission directly from the copyright holder. To view a copy of this licence, visit http://creativecommons.org/licenses/by/4.0/. 


\section{Background}

Hypertension (HTN) is a major global public health concern and is the leading cause of global death or disability [1]. About $30-40 \%$ of the adult population in the developed world suffer from this condition [2]. Despite the availability of many safe, effective, and tolerable medications, the treatment of HTN remains suboptimal [3]. In Egypt, HTN is highly prevalent, and rates of treatment, control, and awareness are relatively low [4]. It was estimated that the prevalence of hypertensive patients among Egyptian adults ( $\geq 25$ years old) was $26.3 \%$. In $60 \%$ of patients, HTN is complicated by the presence of other cardiovascular risk factors, leading to increased cardiovascular morbidity and mortality [5]. About 37\% of hypertensive patients are receiving monotherapy. The 2018 European Society of Cardiology (ESC) and the European Society of Hypertension (ESH) guidelines reported that the following drugs demonstrated effective reduction of blood pressure (BP) and cardiovascular events (CV): calcium channel blockers (CCBs), betablockers, angiotensin-converting enzyme (ACE) inhibitors, angiotensin II receptor blockers (ARBs), and diuretics [6]. They also recommended combination therapy (ACE inhibitor or an ARB with a CCB or diuretic) as initial therapy for most hypertensive patients [7]. Moreover, they stated that patients should be subjected to a three-drug combination if BP not controlled on a two-drug combination [8].

Target BP control in hypertensive patients cannot be achieved without "good" adherence to prescribed medications according to healthcare providers' instructions [9]. According to the observational evidence, the most important causes of poor BP control are the poor adherence to treatment and the lack of therapeutic action, which may correlate with a high risk of CV events [1012]. Poor adherence can be defined as suboptimal daily use of prescribed regimens or early discontinuation of treatment $[13,14]$. It was reported that after 6 months, more than one third of patients stop their initial treatment. This ratio may increase to half of the hypertensive patients after 1 year [15]. Therefore, the simplification of the treatment strategy and development of new approaches for the management of hypertension is a priority to improve the adherence to treatment and BP control [16]. In this study, we aimed to assess the adherence of the fixed-dose combinations (FDC) of available antihypertensive medications in a real-world sample in Egypt by patient self-assessment using the Morisky 8Item Medication Adherence Scale (MMAS 8) [17].

\section{Methods}

We followed Strengthening the Reporting of Observational Studies in Epidemiology (STROBE) statement guidelines when reporting this manuscript. This study was approved by the Egyptian Ministry of Health.

\section{Study design, study setting, and study participants}

This was a multi-center, cross-sectional, observational study that was conducted over a period of 1 year from Jan 2017 to Jan 2018. We included 2000 Egyptian hypertensive patients from 100 centers spanning the Mediterranean coast, Nile Delta region, and southern Egypt.

We included patients meeting the following criteria: (1) males or females aged > 21 years; (2) patients with essential hypertension who were prescribed antihypertensive treatment with FDC for at least 3-month duration. All patients signed informed consent; and (3) patients willing to give written informed consent. We excluded all patients with severe renal impairment (GFR $<30 \mathrm{ml} / \mathrm{min}$ ) or have any one of the following conditions: pregnancy, lactation, secondary hypertension, hypersensitivity to the used medications, or participating in other clinical studies.

\section{Study assessments and data collection}

For each eligible patient, we reported the following data; during the recruitment process, the following data were collected for each patient eligible for the study: sociodemographic characteristics (age, sex, ethnicity, weight, and height), educational status, marital status, and occupation. Furthermore, we collected the data regarding the duration of hypertension, number of previous antihypertensive medications, duration, and type of treatment with FDC of anti-hypertension medications. Moreover, data regarding blood pressure measurements, medical history/comorbidity (e.g., smoking, diabetes, dyslipidemia, peripheral arterial disease, cardiovascular disease, congestive heart disease, and chronic pulmonary disease), family history of hypertension and cardiovascular disease, and self-administrated MMAS 8 questionnaire were obtained. Highly adherent patients were identified with the score of 8 on the scale, medium adherers with a score of 6 to $<8$, and low adherers with a score of $<6$.

All investigators received a formal, standardized training for blood pressure measurements. The blood pressure was assessed in the sitting position following a 5min rest using a standardized automated sphygmomanometer (Omron T9P). A total of three readings were obtained, in which the first reading was discarded and the average of the second and third readings was obtained. Data were collected in the form of case report form (CRF). The CRFs were computerized with the data validation process, in which any raised inconsistencies led to appropriate queries to investigator resolution who is obliged to respond by confirming or modifying the inconsistent data. All of the key data were checked for 
each CRF (absence of missing data and consistency control).

\section{Study objectives}

The primary objective was to measure the percentage of patients highly adherent to the treatment with FDC of anti-hypertension medications. The secondary objectives were to identify different patients' profiles by comparing the characteristics of patients with a high, medium, and low adherence to the medication and to determine the causes of poor adherence to medication.

\section{Sample size calculation}

Assuming that high adherence to treatment would be achieved in $50 \%$ of patients, with $\leq 10 \%$ of patients nonevaluable, enrollment of 2000 patients would provide a precision of $2.3 \%$ in the calculation of the $95 \%$ CI. If the rate of 0adherence were to be either higher or lower than $50 \%$, precision would be better.

\section{Statistical analysis}

All categorical variables were presented in frequency and percentage, whereas numerical variables were presented with mean and SD. Categorical data were described by frequency and percentage. Comparative analysis and inferential statistics were performed using paired $t$ test, Wilcoxon signed-rank, and McNamara test for continuous variables. Chi-square test was used in case of categorical variables. For all statistical tests, $P$ value $\leq 0.05$ was considered statistically significant and the $95 \% \mathrm{CI}$ for the percentage of highly adherent patients has been calculated. Univariate and multivariate logistic regression analyses were applied to identify the predictive factors for achieving high adherence to antihypertensive treatment. Univariate logistic regression considered each factor individually and multivariate considered all factors simultaneously. Multivariate model selection was carried out using stepwise and forward method by removing variables from the model that were not significant. The Hosmer-Lemershow test was used to measure the goodness-of-fit of the logistic regression model with $p$ value $\leq 0.05$ indicating poor fitness of model. Odds ratios (OR) with $95 \%$ confidence intervals (95\% CI) were provided. All statistical tests were performed using SPSS program version 25.

\section{Results}

\section{Baseline characteristics and demographic analysis}

The mean age of enrolled patients was $55.8 \pm 10.9$ years old. The majority of participants were males 1040 (52.0\%). Regarding the physical activity, 451 (22.6\%) were inactive, 676 (33.8\%) with low activity, 667 (33.4\%) with moderate activity, and 206 (10.3\%) with high activity. About two thirds of patients 1503 (75.1\%) never smoke, 299 (15.0\%) smokers, and 198 (9.9\%) quit smoking. All demographics data are presented in Table 1.

The mean systolic blood pressure (SBP) was $140.5 \pm$ $16.8 \mathrm{mmHg}$, and the diastolic blood pressure (DBP) was $86.1 \pm 10.0 \mathrm{mmHg}$. Controlled SBP $(<140 \mathrm{mmHg})$ was presented in $847(42.4 \%)$ patients. In addition, the mean heart rate $(\mathrm{HR})$ was $79 \pm 8.8 \mathrm{beat} / \mathrm{min}$. The mean duration since diagnosis of hypertension was $9.1 \pm 7.3$ years. Interestingly, 1181 (59.1\%) patients have a family history of hypertension, and 461 (23.1\%) have no family history of hypertension.

\section{Previous antihypertensive medications}

Concerning antihypertensive medication, 602 (30.1\%) patients received monotherapy, $606(30.3 \%)$ patients received two types of antihypertensive drugs, 326 (16.3\%) patients received triple combination therapy, and 145 (7.2\%) patients received four types of antihypertensive drugs. The mean duration of treatment with FDC of anti-hypertension medications was $39.2 \pm 36.9$ months. The most frequent combination used was $\mathrm{ARBs} / \mathrm{HCTZ}$ 846 (42.3\%), then 337 (16.9\%) ACE-I/HCTZ, 251 (12.6\%) ARBs/CCB, and 227 (11.4\%) triple combinations (ARBs/CCB/HCTZ). More than $98 \%$ of patients received FDC once time per day.

\section{Medical history and comorbidity}

The most frequent comorbidities were dyslipidemia 987 (49.35\%), diabetes mellitus 885 (44.25\%), obesity 566 (28.3\%), and coronary artery disease 309 (15.45\%). We summarized the medical and surgical history of patients according to the Medical Dictionary for Regulatory Activities (MedDRA) and the concomitant medications in Supplementary file 1 and 2.

\section{Adherence to medication by MMAS}

The mean value of adherence to medication by MMAS was $6.5 \pm 1.9$. Our analysis showed that $41.3 \%$ (95\% CI [39.1 to $43.4 \%]$ ) patients reached the high adherence, $26.2 \%$ (95\% CI [ 24.3 to $28.1 \%$ ]) of patients were medium adherent, and $32.6 \%$ (95\% CI [30.6 to 34.7\%]) of the patients were low adherent to the treatment. The correlation between the medication adherence and patient's demographics is shown in Table 2 and Table 3.

Male patients showed higher adherence rate than females $(56.4 \%$ versus $43.6 \%, p<0.001)$. Higher level of education was significantly associated with high adherence rate: 559 (67.8\%) university level, $232(28.1 \%)$ primary/secondary school, and $34(4.1 \%)$ illiterate, $(p<$ $0.001)$. In addition, once daily (99.2\%) fixed-dose combination was associated with high adherence rate than twice daily $(0.8 \%), p=0.03$. More than $82 \%$ of the high adherent patients were married, and $11.2 \%$ were widowed. There is no significant difference between the 
Table 1 Socio-demographic characteristics of included patients

\begin{tabular}{|c|c|c|}
\hline Parameters & & Patients \\
\hline Age, year & & $55.8 \pm 10.9$ \\
\hline \multirow[t]{2}{*}{ Gender } & Male & $1040(52 \%)$ \\
\hline & Female & $960(48 \%$ \\
\hline Height, cm & & $169.1 \pm 8.3$ \\
\hline Weight, Kg & & $89.5 \pm 16.2$ \\
\hline Body mass index, $\mathrm{Kg} / \mathrm{m}^{2}$ & & $31.4 \pm 5.9$ \\
\hline \multirow[t]{3}{*}{ Blood pressure control } & $\mathrm{SBP}<140 \mathrm{mmHg}$ & $847(42.4 \%)$ \\
\hline & $\mathrm{DBP}<90 \mathrm{mmHg}$ & 1109 (55.5\%) \\
\hline & $\mathrm{BP}<140 / 90 \mathrm{mmHg}$ & $746(37.3 \%)$ \\
\hline \multirow[t]{3}{*}{ Ethnicity } & Middle eastern & $1665(83.3 \%)$ \\
\hline & White/caucasian & $300(15 \%)$ \\
\hline & Black & $35(1.8 \%)$ \\
\hline \multirow[t]{3}{*}{ Educational level } & College/university & 1160 (58\%) \\
\hline & Primary/secondary school & $669(33.5 \%)$ \\
\hline & Illiterate & $171(8.6 \%)$ \\
\hline \multirow[t]{5}{*}{ Employment status } & Full time & $860(43 \%)$ \\
\hline & Retired & 355 (17.8\%) \\
\hline & Housekeeper & $336(16.8 \%)$ \\
\hline & Not employed & $246(12.3 \%)$ \\
\hline & Part time & $203(10.2 \%)$ \\
\hline \multirow[t]{4}{*}{ Marital status } & Married & $1616(80.8 \%)$ \\
\hline & Widowed & $248(12.4 \%)$ \\
\hline & Divorced & 71 (3.6\%) \\
\hline & Single & $65(3.3 \%)$ \\
\hline \multirow[t]{4}{*}{ Patient daily physical activity/exercise level } & Inactive & $451(22.6 \%)$ \\
\hline & Low & $676(33.8 \%)$ \\
\hline & Moderate & $667(33.4 \%)$ \\
\hline & High & $206(10.3 \%)$ \\
\hline \multirow[t]{2}{*}{ Patient have any diet control/regimen for hypertension } & Yes & $641(32.15 \%)$ \\
\hline & No & $1359(68 \%)$ \\
\hline \multirow[t]{3}{*}{ Smoking status } & Never & $1503(75.1 \%)$ \\
\hline & Currently & $299(15 \%)$ \\
\hline & Quit & 198 (9.9\%) \\
\hline
\end{tabular}

Data were presented as mean \pm SD for continuous data and frequency (\%) for categorical variables Percentages. SBP; systolic blood pressure, DBP; diastolic blood pressure, $B P$; blood pressure

smokers or non-smokers regarding to the adherence to medication $(p=0.066)$.

Out of 847 patients with controlled SBP $(<140 \mathrm{mmHg})$, high adherence was found in 387 (51.9\%) patients, medium adherence in $232(27.4 \%)$ patients, and low adherence in 187 (22.1\%) patients as presented in Fig. 1.

Patients with high BMI, SBP, and DBP presented with low adherence to medications with statistically significant difference $(p<0.001)$. Also, patients with long history of hypertension showed lower adherence with medications $(p=0.795)$. In terms of patients with family history, $71.5 \%$ of high adherent patients are presented with a family history of hypertension. There is no significant difference between the scale degrees regarding the duration of treatment with FDC of anti-hypertension medications $(p=0.429)$. The majority of high adherent patients were receiving the combination of ARBs/HCTZ (47.0\%) and ACE-I/HCTZ (14.4\%, Fig. 2). Multivariate logistic regression analysis showed that patients with high level of education, employed patients, and patients with low SPB, DBP, and heart rate have high adherence rate to medication as seen in Table 4 . 
Table 2 Adherence to the medication comparison with the categorical baseline parameters

\begin{tabular}{|c|c|c|c|c|c|}
\hline Parameters & & High $(n=825)$ & Medium $(n=523)$ & Low $(n=652)$ & $P$ value \\
\hline \multirow[t]{2}{*}{ Gender } & Male & $465(56.4 \%)$ & 277 (53\%) & $298(45.7 \%)$ & $<0.001$ \\
\hline & Female & $360(43.6 \%)$ & $246(47 \%)$ & $354(54.3 \%)$ & \\
\hline \multirow[t]{3}{*}{ Ethnicity } & Middle eastern & 717 (86.9\%) & 405 (77.4\%) & $543(83.3 \%)$ & $<0.001$ \\
\hline & White/caucasian & $100(12.1 \%)$ & $106(20.3 \%)$ & $94(14.4 \%)$ & \\
\hline & Black & $8(1 \%)$ & $12(2.3 \%)$ & $15(2.3 \%)$ & \\
\hline \multirow[t]{3}{*}{ Educational level } & College/university & $559(67.8 \%)$ & $310(59.3 \%)$ & 291 (44.6\%) & $<0.001$ \\
\hline & Primary/secondary school & $232(28.1 \%)$ & 164 (31.4\%) & $273(41.9 \%)$ & \\
\hline & Illiterate & $34(4.1 \%)$ & $49(9.4 \%)$ & $88(13.5 \%)$ & \\
\hline \multirow[t]{4}{*}{ Marital status } & Married & $678(82.2 \%)$ & $431(82.4 \%)$ & $507(77.8 \%)$ & 0.017 \\
\hline & Widowed & $92(11.2 \%)$ & $51(9.8 \%)$ & $105(16.1 \%)$ & \\
\hline & Divorced & $25(3 \%)$ & $22(4.2 \%)$ & $24(3.7 \%)$ & \\
\hline & Single & $30(3.6 \%)$ & $19(3.6 \%)$ & $16(2.5 \%)$ & \\
\hline \multirow[t]{5}{*}{ Employment status } & Full time & $423(51.3 \%)$ & $220(42.1 \%)$ & $217(33.3 \%)$ & $<0.001$ \\
\hline & Retired & $163(19.8 \%)$ & 85 (16.3\%) & $107(16.4 \%)$ & \\
\hline & Housekeeper & $96(11.6 \%)$ & $74(14.1 \%)$ & $166(25.5 \%)$ & \\
\hline & Not employed & $64(7.8 \%)$ & 77 (14.7\%) & $105(16.1 \%)$ & \\
\hline & Part time & $79(9.6 \%)$ & $67(12.8 \%)$ & $57(8.7 \%)$ & \\
\hline \multirow[t]{4}{*}{ Patient daily physical activity/exercise level } & Inactive & $160(19.4 \%)$ & $116(22.2 \%)$ & $175(26.8 \%)$ & $<0.001$ \\
\hline & Low & $266(32.2 \%)$ & $154(29.4 \%)$ & $256(39.3 \%)$ & \\
\hline & Moderate & $307(37.2 \%)$ & $191(36.5 \%)$ & $169(25.9 \%)$ & \\
\hline & High & $92(11.2 \%)$ & $62(11.9 \%)$ & $52(8.0 \%)$ & \\
\hline \multirow[t]{2}{*}{ Patient have any diet control/regimen } & No & $523(63.4 \%)$ & $338(64.6 \%)$ & $498(76.4 \%)$ & $<0.001$ \\
\hline & Yes & $302(36.6 \%)$ & $185(35.4 \%)$ & $154(23.6 \%)$ & \\
\hline \multirow[t]{3}{*}{ Smoking status } & Never & $646(78.3 \%)$ & $387(74.0 \%)$ & $470(72.1 \%)$ & 0.066 \\
\hline & Currently & $108(13.1 \%)$ & $78(14.9 \%)$ & $113(17.3 \%)$ & \\
\hline & Quit & $71(8.6 \%)$ & $58(11.1 \%)$ & $69(10.6 \%)$ & \\
\hline \multirow[t]{2}{*}{ Family history of HTN } & Yes & $500(71.5 \%)$ & $294(69.5 \%)$ & $387(74.4 \%)$ & 0.236 \\
\hline & No & $199(28.5 \%)$ & $129(30.5 \%)$ & $133(25.6 \%)$ & \\
\hline \multirow[t]{2}{*}{ Frequency/day of last fixed-dose combination } & Once & $818(99.2 \%)$ & $513(98.1 \%)$ & $635(97.4 \%)$ & 0.031 \\
\hline & Twice & 7 (0.8\%) & 10 (1.9\%) & 17 (2.6\%) & \\
\hline
\end{tabular}

\section{Discussion}

In this cross-sectional study, we investigated the adherence of hypertensive patients to antihypertensive medications. Our findings showed that $41.3 \%$ of Egyptian hypertensive patients were highly adherent to antihypertensive medications. Interestingly, about $60 \%$ of patients have a family history with hypertension. The most frequent dual combinations were ARBs \& HCTZ, ACE-I \& HCTZ, ARBs \& CCB; while, the most frequent triple combination is ARBs, CCB \& HCTZ. Moreover, half of those patients have dyslipidemia, and $44.25 \%$ are suffering from diabetes mellitus. In terms of MMRS, $41.3 \%$ of patients had high adherence, $26.2 \%$ had medium adherence, and $32.6 \%$ had low adherence. These results are

Table 3 Adherence to the medication comparison with the continuous baseline parameters

\begin{tabular}{lllll}
\hline Parameters & High $(n=825)$ & Medium $(n=523)$ & Low $(n=652)$ & $P$ value \\
\hline Age, year & $55.6 \pm 11.1$ & $55.8 \pm 10.5$ & $56.0 \pm 11.1$ & 0.823 \\
BMl, $\mathrm{Kg} / \mathrm{m} 2$ & $30.4 \pm 5.2$ & $31.3 \pm 5.7$ & $32.7 \pm 6.6$ & $<0.001$ \\
SBP, $\mathrm{mmHg}$ & $137 \pm 15.6$ & $138.8 \pm 15.7$ & $145.9 \pm 18.0$ & $<0.001$ \\
DBP, $\mathrm{mmHg}$ & $84.4 \pm 9.3$ & $85.0 \pm 9.5$ & $89.1 \pm 10.4$ & $<0.001$ \\
\hline
\end{tabular}




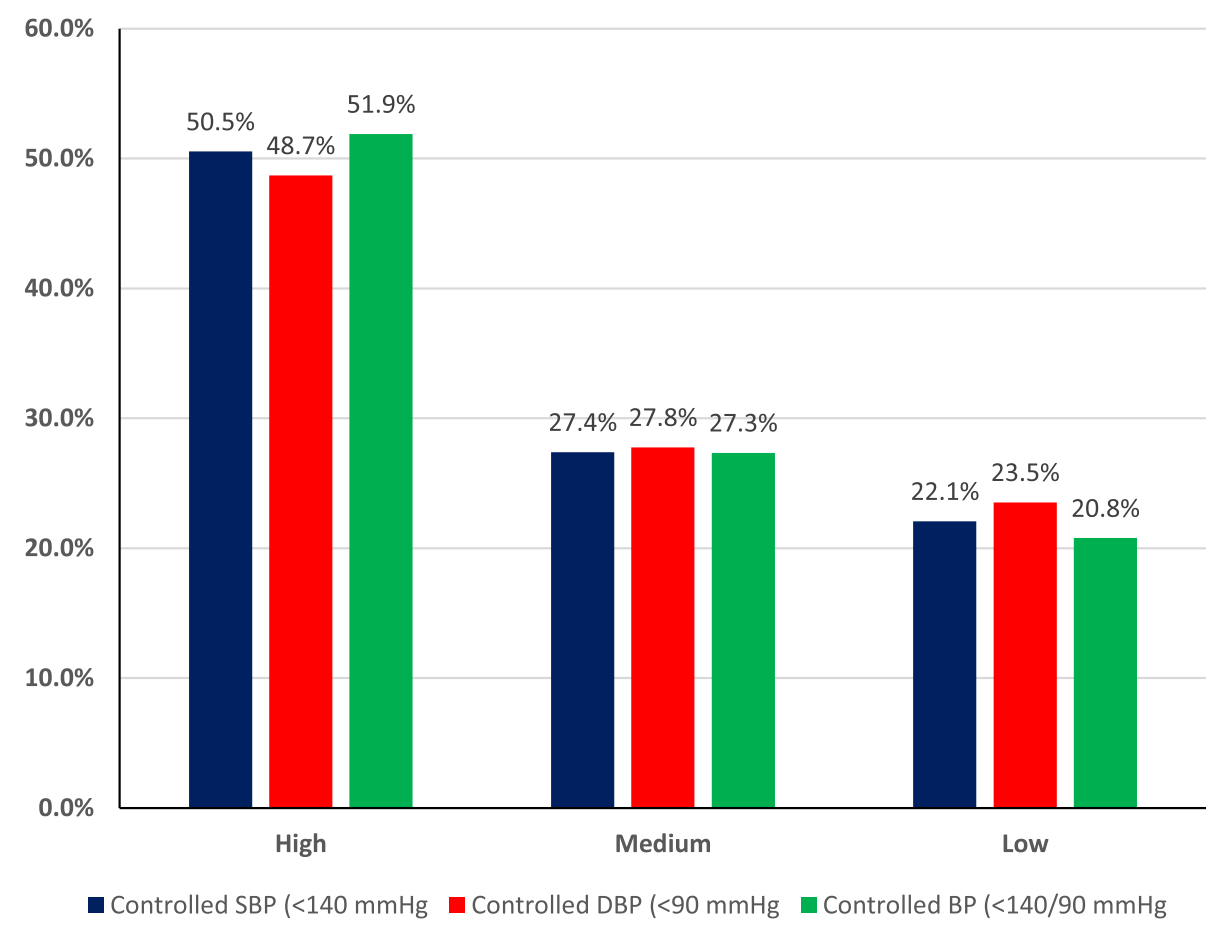

Fig. 1 Adherence to the medication comparison with blood pressure control

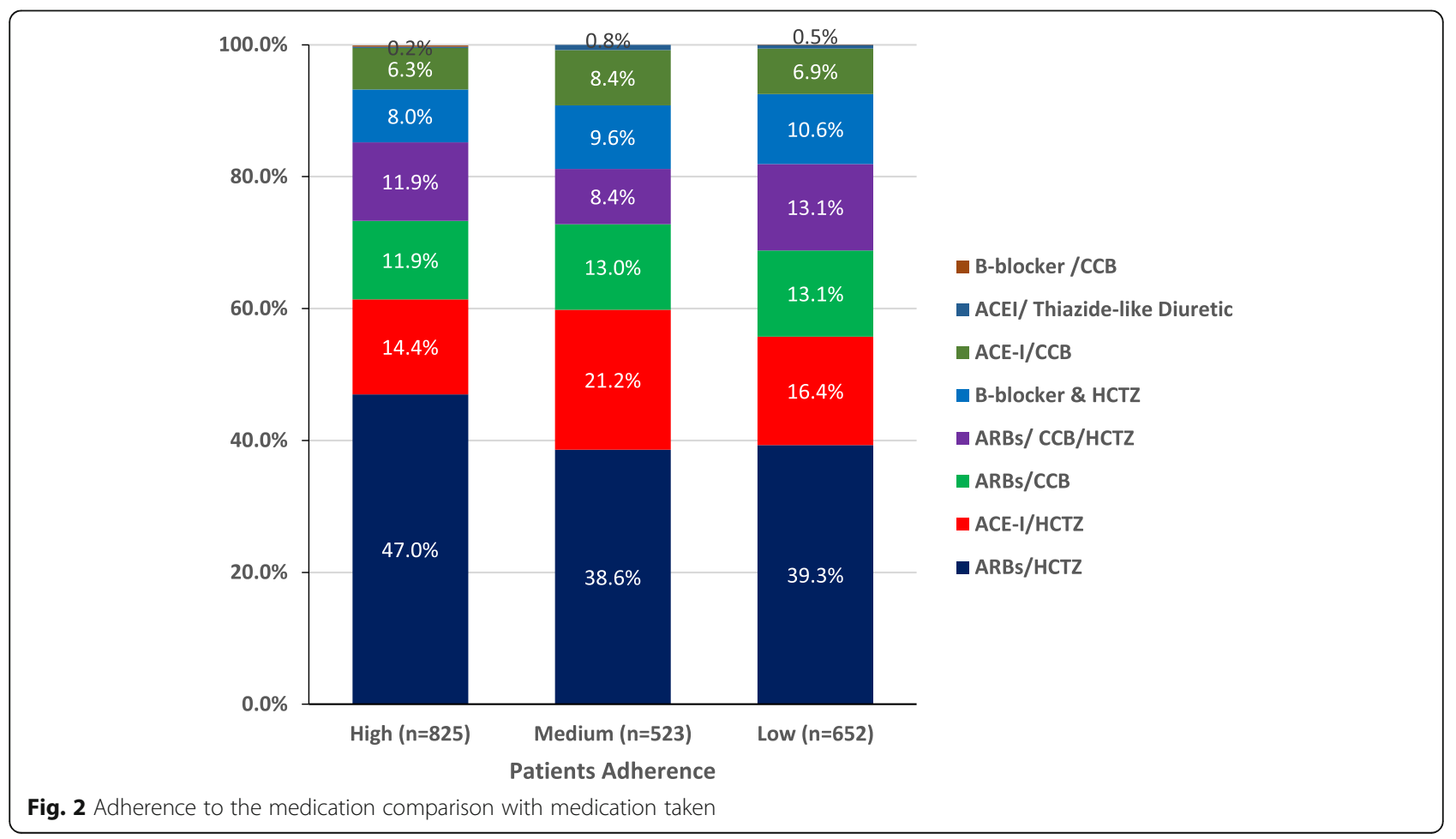


Table 4 Univariate and multivariate logistic regression analysis to identify the significant predictor variables for high adherence to medication

\begin{tabular}{|c|c|c|c|c|c|c|}
\hline \multirow[t]{2}{*}{ Parameters } & \multicolumn{3}{|c|}{ Univariate analysis } & \multicolumn{3}{|c|}{ Multivariate analysis } \\
\hline & $\mathrm{OR}$ & $95 \% \mathrm{Cl}$ for $\mathrm{OR}$ & $P$ value & $\mathrm{OR}$ & $95 \% \mathrm{Cl}$ for $\mathrm{OR}$ & $P$ value \\
\hline Age & 1.007 & 0.994 to 1.021 & 0.277 & - & - & - \\
\hline Gender (ref: female) & 1.016 & 0.781 to 1.322 & 0.906 & - & - & - \\
\hline Race (ref: non-middle eastern) & 1.296 & 0.95 to 1.753 & 0.092 & - & - & - \\
\hline \multicolumn{7}{|l|}{ Education (ref: illiterate) } \\
\hline Primary/secondary school & 1.638 & 0.950 to 2.824 & 0.076 & 1.70 & 0.998 to 2.896 & $0.05^{*}$ \\
\hline College/university & 2.191 & 1.270 to 3.778 & $0.005^{*}$ & 2.354 & 1.387 to 3.994 & $0.002^{*}$ \\
\hline Marital status (ref: not married) & 0.840 & 0.622 to 1.133 & 0.253 & - & - & - \\
\hline Employment (ref: non employer) & 1.681 & 1.258 to 2.247 & $<0.001^{*}$ & 1.485 & 1.171 to 1.883 & $0.001^{*}$ \\
\hline Smoking (ref: smoker) & 1.416 & 1.023 to 1.96 & $0.036^{*}$ & - & - & - \\
\hline $\mathrm{BMl}, \mathrm{Kg} / \mathrm{m}^{2}$ & 0.974 & 0.946 to 1.003 & 0.082 & - & - & - \\
\hline BMI (ref: > 30 Kg/m²) & 1.102 & 0.793 to 1.531 & 0.562 & - & - & - \\
\hline $\mathrm{SBP}, \mathrm{mmHg}$ & 0.988 & 0.979 to 0.998 & $0.016^{*}$ & 0.989 & 0.980 to 0.998 & $0.021^{*}$ \\
\hline $\mathrm{DBP}, \mathrm{mmHg}$ & 0.983 & 0.967 to 0.999 & $0.033^{*}$ & 0.981 & 0.966 to 0.996 & $0.015^{*}$ \\
\hline $\mathrm{HR}$, beat/min & 0.969 & 0.955 to 0.983 & $<0.001^{*}$ & 0.965 & 0.951 to 0.978 & $<0.001^{*}$ \\
\hline Duration of HTN & 1.004 & 0.987 to 1.022 & 0.61 & - & - & - \\
\hline Family history of HTN (ref: no family history) & 0.918 & 0.717 to 1.174 & 0.493 & - & - & - \\
\hline \multicolumn{7}{|l|}{ Antihypertensive treatment (ref: ARBs/HCTZ) } \\
\hline ACE-I/HCTZ & 0.622 & 0.452 to 0.858 & 0.114 & & & \\
\hline ACE-I/CCB & 0.998 & 0.652 to 1.528 & 0.993 & & & \\
\hline ARBs/CCB & 0.806 & 0.567 to 1.145 & 0.229 & & & \\
\hline ARBs/CCB/HCTZ & 0.773 & 0.526 to 1.136 & 0.190 & - & - & - \\
\hline$\beta$-blocker/HCTZ & 0.732 & 0.496 to 1.082 & 0.118 & & & \\
\hline ACEI/thiazide-like diuretic & 0.358 & 0.063 to 2.037 & 0.247 & & & \\
\hline$\beta$-blocker and CCB & 1.335 & 0.178 to 10.008 & 0.779 & & & \\
\hline
\end{tabular}

somewhat different from those of Tilea et al. [12] who reported better adherence rates : $69.8 \%$ of patients had high adherence, $20.3 \%$ had medium adherence, and 9.9\% had low adherence through a prescription record review tool. However, some studies reported high levels of nonadherence to antihypertensive treatment. In a crosssectional study performed in Ghana and Nigeria, 66.7\% of patients were non-adherent to treatment. Nonadherence was related to age (younger patients) and education level [18]. In contrast, our results documented that high adherence rates were more often associated with male gender, middle eastern ethnicity, high level of education, full-time workers, and married persons. These findings are similar to those of Tilea et al. [12], Daniel and Veiga [19], Karakurt and Kaşikçi [20], and Tibebu et al [21].

Daniel and his colleagues found that adherence to therapy was better in the age group of 40-59 years and those $>80$ years of age, and that the most highly adherent participants were $61-70$ years old (31.4\%). Moreover,
32 of these patients in the age group of 51-60 years (30.5\%) had a moderate adherence, and half of their hypertensive patients who had low adherence rates (< $20 \%)$ to treatment were in the age group of 51-60 years, and, demonstrating significant $(p=0.0001)$ effects of age on treatment adherence [19]. Similarly, Bandi et al. reported that the higher prevalence of medication adherence was observed in older patients (34.0\%) when compared to young patients $(24.5 \%, p=0.001)$. They explained this by the heavy alcohol consumption, lower education level, and lower knowledge of hypertension control in young patients [22].

Regarding the adherence difference in gender classification, we found that males showed highly significant adherence to treatment compared to females $(56.4 \%$ versus $43.6 \%, p<0.001)$. In contrast, Ambaw et al. reported that men were found to be less adherent when compared to women. They added that men are loaded by the outdoor activities which make them busy and make them forget their medications [23]. 
In this study, we found that highly educated and fulltime employed patients showed high adherence to antihypertensive medications. In contrast, Lee et al. demonstrated that patients with primary or low education and patients who were unemployed or retired were more likely to be compliant [24]. This difference can be explained by the fact that medical service was relatively accessible in Hong Kong.

We found a significant difference between the MMAS degrees according to the number of previous antihypertensive medications; increased numbers of antihypertensive drugs are associated with intermediate and poor adherence $(p=0.019)$. This finding is similar to those of Mallat et al. [25] who found that increased numbers of antihypertensive drugs prescribed in the presence of comorbidities are associated with poor adherence. However, the available evidence is not yet sufficient to conclude that there are differences between an FDC and to free combination therapy in the management of HTN [26].

Treatment cost is one of the main driven factor of high non-adherence rates across all therapeutic areas, and the financial burden of the increasing cost of treatment can limit patients access to treatment, regardless of other determinants of socio-economic status [11, 27]. Previous reports showed that drug cost is accounted for a substantial proportion of drug non-adherence [28]. In the present study, there was no financial coverage of prescribed drugs which can limit our findings due to lack of standardization of this confounding factor.

Good doctor-patient communication, adequate knowledge, awareness of the disease and its possible complications, as well as the use of special containers for drug dispensing (blister packs, bottles, and timed dosing batches), remembering to renew the prescriptions, and then affording the price of the medication are important elements that affect the adherence to the treatment plan $[20,29,30]$.

\section{Conclusion}

In an Egyptian hypertensive population treated with FDCs, higher medication adherence rates were associated with higher education level, middle eastern ethnicity, employed patients, and lower BP levels. Patients with high adherence had lower BP levels and lower BMI as compared with patients with medium and low adherence. Developing awareness through patient education programs could increase patients' adherence to their medication.

\section{Supplementary information}

Supplementary information accompanies this paper at https://doi.org/10. 1186/s43044-020-00044-6.

Additional file 1:. Medical History / Co-morbidity

Additional file 2:. Concomitant Medication

\section{Abbreviations}

ACE: Angiotensin-converting enzyme; ARBs: Angiotensin II receptor blockers; BP: Blood pressure; CCBs: Calcium channel blockers; CRF: Case report form; CV: Cardiovascular events; DBP: Diastolic blood pressure; ESC: European Society of Cardiology; FDC: Fixed-dose combination; HTN: Hypertension; MedDRA: Medical Dictionary for Regulatory Activities; MMAS 8: Morisky 8Item Medication Adherence Scale; SBP: Systolic blood pressure;

STROBE: Strengthening the Reporting of Observational Studies in

Epidemiology

\section{Acknowledgements}

The author thank the study participants and the following investigators for their active participation: Tarek Hafez, Hossam Arafa, Mohamed Anwar, Raafat Zakhary, Onsy Rofaeil, Ramzy Riad, Mohamed El Nazer, Magdy Badie Guirges, Ahmed Saher, Amr Sabry, ElSayed El Shafei, Ashraf el Shayb, Maher Helmy, Samir Kamal, Atwa Yassin, Youssef Alfons, Hamid Ahmed, Ashraf Riad, Albert Anwar, Ayman El Sebaie, Khaled Leon, Hamdy Soliman, Hisham Rafae, Sherif ElZehwy, Abbas Aly Orabi, Ibrahim Zamam, Mohamed Hussein El Maghraby, Kamal Agban, Khaled El Sayed Abdel Latif, Ibrahim Sabry, Ibrahim Mousa, Rabab Muhammad Maher, Sherif Azmy, Ehab Mofied, Mostafa Abdelaziz, Hossam Mansour, Tarek Youssef, Mohamed ElOkaby, Khaled Dahshan, Nader ElShahat, Atef ElBehiry, Abou ElMaaty Mohamed, Gerges Romany, Nader Wadie, Mohamed Moussa, Mohamed Halawa, Mohamed ElTayeb Nasser, Ahmed AbdelAleem, Aly Hassan Taher, Nabil Nassif, Mohamed Ibrahim Lotfy, Hossam Awad, Magdy AbdelHamid, Ahmed Tamara, Mohamed ElSakhawy, Maged Iskandar, Mostafa Mekreb, Hany Amin, Hossam Badr, Mohamed Saad, Mohamed Wafaie, Hatem Younes, Ahmed ElSayed Badawy, Ashraf Shehata, Micheal Lamaey, Sayed Abdel Hafiz, Tarek El Naggar, Ashraf Abdallah, Nabil Gobran, Wagdy Samour, Omar Osman, Abdallah Mostafa, Akmal Kamal, Mohamed Abdel Latif, Ayman Morttada, Amir El Okely, Yasser Mohamed Huzayen, Mazen Tawfik, Ahmed AbdelSalam, Helmy Shalaby, Mohamed Fahmy AbdlAziz, Adel Boshra, Adel Farag, and Seif Abu Seif. The statistical analysis report was provided by the RAY Contract Research Organization. Editorial support was provided by Dr. Hussien Ahmed of RAY Contract Research Organization.

\section{Authors' contributions}

Dr. Mahmoud Mohamed Hassanein was responsible for the study idea, study design, data collection, statistical analysis, and writing the final draft of the manuscript. All authors read and approved the final manuscript.

\section{Funding}

The study was sponsored and funded by Sanofi; Sanofi was involved in the study design, collection, analysis, and interpretation of the data, as well as data checking of information provided in the manuscript. However, ultimate responsibility for opinions, conclusions, and data interpretation lies with the author.

\section{Availability of data and materials}

The datasets generated during the current study are not publicly available but are available from the corresponding author on reasonable request.

\section{Ethics approval and consent to participate}

This study was approved by the Egyptian Ministry of Health (Reference number: IRBEHL07942). Written informed consent was obtained from each participant.

\section{Consent for publication}

Not applicable

\section{Competing interests}

I am the editor-in-Chief of the Egyptian heart journal, but I am not handling this manuscript. I am blinded to the reviewers. The author declares that there are no competing interests.

Received: 8 October 2019 Accepted: 19 February 2020

Published online: 05 March 2020

References

1. Forouzanfar MH, Afshin A, Alexander LT et al (2016) Global, regional, and national comparative risk assessment of 79 behavioural, environmental and 
occupational, and metabolic risks or clusters of risks, 1990-2015: a systematic analysis for the Global Burden of Disease Study 2015. Lancet 388(10053):1659-1724. https://doi.org/10.1016/S0140-6736(16)31679-8

2. Chockalingam A, Campbell NR, Fodor JG (2006) Worldwide epidemic of hypertension. Can J Cardiol 22(7):553-555

3. Ibrahim MM, Rizk H, Appel LJ et al (1995) Hypertension prevalence, awareness, treatment, and control in Egypt. Results from the Egyptian National Hypertension Project (NHP). NHP Investigative Team. Hypertension 26(6 Pt 1):886-890

4. Voskuil M, Verloop WL, Blankestijn PJ, Agostoni P, Stella PR, Doevendans PA (2011) Percutaneous renal denervation for the treatment of resistant essential hypertension; the first Dutch experience. Netherlands Hear J 19(78):319-323. https://doi.org/10.1007/s12471-011-0143-z

5. Ibrahim MM (2013) Problem of hypertension in Egypt. Egypt Hear J 65(3): 233-234. https://doi.org/10.1016/j.ehj.2013.03.005

6. Williams B, Mancia G, Spiering W et al (2018) 2018 ESC/ESH Guidelines for the management of arterial hypertension. Eur Heart J 39(33):3021-3104. https://doi.org/10.1093/eurheartj/ehy339

7. ALLHAT Officers and Coordinators for the ALLHAT Collaborative Research Group (2002) The Antihypertensive and Lipid-Lowering Treatment to Prevent Heart Attack Trial. Major outcomes in high-risk hypertensive patients randomized to angiotensin-converting enzyme inhibitor or calcium channel blocker vs diuretic: the antihypertensive and lipid-lowering treatment to prevent heart attack trial (ALLHAT). JAMA 288(23):2981-2997

8. Wald DS, Law M, Morris JK, Bestwick JP, Wald NJ (2009) Combination therapy versus monotherapy in reducing blood pressure: meta-analysis on 11,000 participants from 42trials. Am J Med 122(3):290-300. https://doi.org/ 10.1016/j.amjmed.2008.09.038

9. Gale NK, Greenfield S, Gill P, Gutridge K, Marshall T (2011) Patient and general practitioner attitudes to taking medication to prevent cardiovascular disease after receiving detailed information on risks and benefits of treatment: a qualitative study. BMC Fam Pract 12(1):59. https:// doi.org/10.1186/1471-2296-12-59

10. Abushouk Al, El-Husseny MWA, Bahbah El et al (2017) Peroxisome proliferator-activated receptors as therapeutic targets for heart failure. Biomed Pharmacother 95(June):692-700. https://doi.org/10.1016/j.biopha. 2017.08.083

11. Vrijens B, Antoniou S, Burnier M, de la Sierra A, Volpe M (2017) Current situation of medication adherence in hypertension. Front Pharmacol 8:100. https://doi.org/10.3389/fphar.2017.00100

12. Tilea I, Petra D, Voidazan S, Ardeleanu E, Varga A (2018) Treatment adherence among adult hypertensive patients: a cross-sectional retrospective study in primary care in Romania. Patient Prefer Adherence 12: 625-635. https://doi.org/10.2147/PPA.S162965

13. Mazzaglia G, Ambrosioni E, Alacqua M et al (2009) Adherence to antihypertensive medications and cardiovascular morbidity among newly diagnosed hypertensive patients. Circulation 120(16):1598-1605. https://doi. org/10.1161/CIRCULATIONAHA.108.830299

14. Krousel-Wood M, Joyce C, Holt E et al (2011) Predictors of decline in medication adherence. Hypertension 58(5):804-810. https://doi.org/10.1161/ HYPERTENSIONAHA.111.176859

15. Naderi SH, Bestwick JP, Wald DS (2012) Adherence to drugs that prevent cardiovascular disease: meta-analysis on 376,162 patients. Am J Med 125(9): 882-887.e1. https://doi.org/10.1016/j.amjmed.2011.12.013

16. Egan BM, Zhao Y, Li J et al (2013) Prevalence of optimal treatment regimens in patients with apparent treatment-resistant hypertension based on office blood pressure in a community-based practice network. Hypertension 62(4): 691-697. https://doi.org/10.1161/HYPERTENSIONAHA.113.01448

17. Krousel-Wood M, Islam T, Webber LS, Re RN, Morisky DE, Muntner P (2009) New medication adherence scale versus pharmacy fill rates in seniors with hypertension. Am J Manag Care 15(1):59-66

18. Boima V, Ademola AD, Odusola AO et al (2015) Factors associated with medication nonadherence among hypertensives in Ghana and Nigeria. Int J Hypertens 2015:1-8. https://doi.org/10.1155/2015/205716

19. Daniel ACQG, Veiga EV (2013) Factors that interfere the medication compliance in hypertensive patients. Einstein (Sao Paulo) 11(3):331-337

20. Karakurt $P$, Kaşikçi M (2012) Factors affecting medication adherence in patients with hypertension. J Vasc Nurs 30(4):118-126. https://doi.org/10. 1016/j.jvn.2012.04.002

21. Tibebu A, Mengistu D, Bulto LN (2017) Adherence to prescribed antihypertensive medications and associated factors for hypertensive patients attending chronic follow-up units of selected public hospitals in Addis Ababa, Ethiopia. Int J Health Sci (Qassim) 11(4):47-52

22. Bandi P, Goldmann E, Parikh NS, Farsi P, Boden-Albala B (2017) Age-related differences in antihypertensive medication adherence in Hispanics: a crosssectional community-based survey in New York City, 2011-2012. Prev Chronic Dis 14:E57. https://doi.org/10.5888/pcd14.160512

23. Ambaw AD, Alemie GA, SM W/Y, Mengesha ZB (2012) Adherence to antihypertensive treatment and associated factors among patients on follow up at University of Gondar Hospital, Northwest Ethiopia. BMC Public Health 12:282. https://doi.org/10.1186/1471-2458-12-282

24. Lee GKY, Wang HHX, Liu KQL, Cheung Y, Morisky DE, Wong MCS (2013) Determinants of medication adherence to antihypertensive medications among a Chinese population using Morisky Medication Adherence Scale. PLoS One 8(4):e62775. https://doi.org/10.1371/journal.pone.0062775

25. Mallat SG, Tanios BY, Itani HS, Lotfi T, Akl EA (2016) Free versus fixed combination antihypertensive therapy for essential arterial hypertension: a systematic review and meta-analysis. PLoS One 11(8):e0161285. https://doi. org/10.1371/journal.pone.0161285

26. Lee HJ, Jang S-I, Park E-C (2017) Effect of adherence to antihypertensive medication on stroke incidence in patients with hypertension: a populationbased retrospective cohort study. BMJ Open 7(6):e014486. https://doi.org/ 10.1136/bmjopen-2016-014486

27. Fischer MA, Stedman MR, Lii J et al (2010) Primary medication nonadherence: analysis of 195,930 electronic prescriptions. J Gen Intern Med 25(4):284-290. https://doi.org/10.1007/s11606-010-1253-9

28. Hovstadius B, Petersson G (2011) Non-adherence to drug therapy and drug acquisition costs in a national population - a patient-based register study. BMC Health Serv Res 11(1):326. https://doi.org/10.1186/1472-6963-11-326

29. Schoenthaler A, Knafl GJ, Fiscella K, Ogedegbe G (2017) Addressing the Social Needs of Hypertensive Patients. Circ Cardiovasc Qual Outcomes 10(9). https://doi.org/10.1161/CIRCOUTCOMES.117.003659

30. Abbas H, Kurdi M, Watfa M, Karam R (2017) Adherence to treatment and evaluation of disease and therapy knowledge in Lebanese hypertensive patients. Patient Prefer Adherence 11:1949-1956. https://doi.org/10.2147/ PPA.S142453

\section{Publisher's Note}

Springer Nature remains neutral with regard to jurisdictional claims in published maps and institutional affiliations.

\section{Submit your manuscript to a SpringerOpen ${ }^{\circ}$ journal and benefit from:}

- Convenient online submission

- Rigorous peer review

- Open access: articles freely available online

High visibility within the field

- Retaining the copyright to your article

Submit your next manuscript at $>$ springeropen.com 